\title{
Is cricket courtship song condition dependent?
}

\author{
DAVID A. GRAY*† \& GILLIAN ECKHARDT* \\ *Department of Biological Sciences, Brock University \\ $\dagger$ Department of Biology, The University of Lethbridge \\ (Received 11 October 2000; initial acceptance 5 December 2000; \\ final acceptance 4 April 2001; MS. number: A8908R)
}

\begin{abstract}
Females of the Texas trilling field cricket, Gryllus texensis, show mating preferences based on male courtship song. To test experimentally the condition dependence of courtship song, we attempted to manipulate male condition via the diet. When the diet was manipulated at the adult moult, there was no effect on subsequent male courtship song or male condition measured as residual mass. When the diet was manipulated three moults prior to the adult moult, there was a significant effect on male residual mass, but no differences in courtship song were observed. To gain a second measure of condition in the diet-manipulated-as-nymphs group, we extracted their fat using petroleum ether in a refluxing Soxhlet apparatus. Crickets reared on the poor diet showed a clear relationship between the residual mass measure of condition and condition measured as energetic fat reserve, whereas the two measures of condition were unrelated in crickets reared on the good diet. Courtship song was unrelated to diet, fat reserve or residual mass. We conclude that courtship song does not reflect male condition in the laboratory despite its energetic cost. When given a mating opportunity it is probably in the evolutionary interest of males in poor condition to signal at as high a rate as males in good condition.
\end{abstract}

() 2001 The Association for the Study of Animal Behaviour

Condition dependence of male sexual ornaments may provide a mechanism by which choosy females benefit from mate choice. If production of an attractive mating signal requires substantial energetic cost, then it is possible that only males in good phenotypic condition will produce those attractive signals. To the extent that phenotypic condition reflects genomic attributes that are heritable, females choosing such males as mates may acquire 'good genes' for their offspring; this possibility has been the subject of a great deal of research and debate (Andersson 1994; Johnstone 1995; Møller \& Alatalo 1999). A much less recognized possibility is that males in poor phenotypic condition will produce energetically costly attractive signals despite their poor condition, possibly suffering an increased risk of mortality as a consequence. Although the basic trade-off between current and future reproduction is widely recognized in the life-history literature, it has been under-appreciated by those studying mate choice (but see Kokko 1997; Candolin 1999).

The acoustic communication system of field crickets is ideal for testing some of these ideas. Male crickets

Correspondence and present address: D. A. Gray, Department of Biology, The California State University, Northridge, 18111 Nordhoff Street, Northridge, CA 91330-8303, U.S.A. (email: dave.gray@csun.edu). G. Eckhardt is now at the Department of Biological Sciences, Brock University, St Catharines, ON L28 3A1, Canada.

$0003-3472 / 01 / 110871+07 \$ 35.00 / 0$ produce three types of acoustic signals, an aggressive song during encounters with other males and two distinct types of mating signals, the long-range calling song used to attract females from a distance, and the quieter courtship song used just prior to mating (Alexander 1961). Female preferences based on male calling song have been studied extensively (e.g. Ulagaraj \& Walker 1975; Pollack \& Hoy 1979; Doherty 1985; Hedrick 1986; Simmons 1988; Doherty \& Callos 1991; Forrest \& Green 1991; Doherty \& Storz 1992; Simmons \& Zuk 1992; Wagner et al. 1995; Doherty \& Howard 1996; Simmons \& Ritchie 1996; Wagner 1996; Gray 1997; Hedrick \& Weber 1998; Gray \& Cade 1999a, b; Gray \& Cade 2000; Shaw 2000; Shaw \& Herlihy 2000). Female preferences based on male courtship song have received much less attention (Crankshaw 1979; Burk 1983; Boake 1984; Libersat et al. 1994; Balakrishnan \& Pollack 1996; Nelson \& Nolen 1997; Wagner \& Reiser 2000; M. J. Fitzpatrick, D. A. Gray $\&$ W. H. Cade, unpublished data). When males produce calling song, receptive females may or may not be within acoustic range. In contrast, when males produce courtship song, the male and the female are in very close proximity, and so the probability of courtship resulting in a mating is usually high. In laboratory experiments with virgin females the probability of mating is often 70\% or more (Adamo \& Hoy 1994; Balakrishnan \& Pollack 1996, 1997; Fitzpatrick et al., unpublished data) thus providing strong incentive to males to maximize 

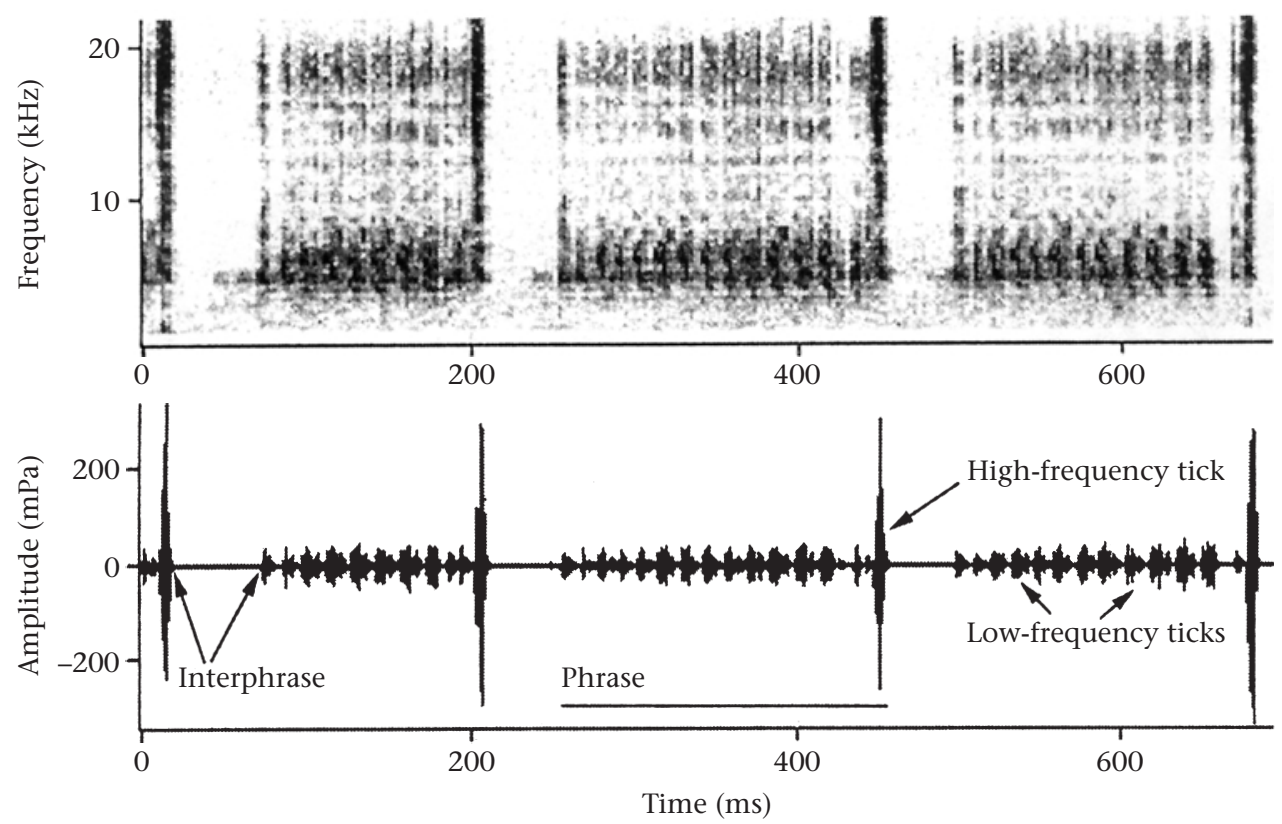

Figure 1. The courtship song of Gryllus texensis. The measured song components were the interphrase interval length, the high-frequency tick period, and the number of low-frequency ticks per high-frequency tick period.

their display, and thereby potentially reveal differences in quality.

In this study we address the condition dependence of male courtship song in the field cricket Gryllus texensis Cade and Otte. Previous work with this species (Fitzpatrick et al., unpublished data) has shown that females are more likely to mate with males producing courtship song with a short interval between the two types of song components, the high- and low-frequency ticks. We term the combined series of low-frequency ticks plus the high-frequency tick a 'phrase' of courtship song and the silent period the 'interphrase interval' (see Fig. 1). Cricket courtship song is known to be energetically expensive, approximately 2.5 times the expense of calling song production in a chirping species, the house cricket, Acheta domesticus (Hack 1998) and so may be constrained by male condition.

In an effort to increase experimentally the variance in male condition, we have attempted to manipulate male condition via the diet, and observe subsequent effects on courtship song, if any. We measured condition as the residuals from a regression of male mass on body size, where body size was measured as the width of the pronotum. Males heavy for their size were considered to be in good condition, whereas males light for their size were considered to be in poor condition. Such a definition of condition has been widely adopted by researchers working with taxa such as fish (Bolger \& Connolly 1989; Milinski \& Bakker 1990; Knapp 1995), birds (Møller 1994; Sheldon et al. 1997; Radford \& Blakely 2000) and insects (Droney 1998), including crickets and katydids (Brown et al. 1996; Brown 1997; Gwynne \& Bailey 1999; Wagner \& Hoback 1999). To our knowledge, there have been no experimental demonstrations in insects that this measure of condition reflects the accumulated fat reserves of individuals. To obtain a second measure of condition, we extracted the fat from a subset of our experimental subjects. The extent to which these two measures of condition assess the same properties of organisms is of additional interest in many systems.

\section{METHODS}

\section{General Methods}

Crickets were from laboratory stock derived from Austin, Texas, U.S.A. approximately four generations previously. We reared stock crickets at $28 \pm 1{ }^{\circ} \mathrm{C}$ on a $14: 10 \mathrm{~h}$ light:dark cycle in plastic tubs provided with cardboard shelter, dry cat food (Purina Cat Chow, Ralston Purina, Mississauga, Ontario, Canada), and water in cottonplugged vials. We conducted two diet manipulations, differing in the stage of cricket development that the diets were assigned. In the first experimental group, we assigned diets randomly to adults within $24 \mathrm{~h}$ of the adult moult. In the second, we assigned the diets randomly within $24 \mathrm{~h}$ of moult to the nymphal stadium three additional moults away from adulthood. The dietary treatments were ad libitum and consisted of a continuation of the cat food diet (good diet treatment) or a diet of ground soybean meal and wheat chaff (50\% of each by mass; bad diet treatment). The bad diet is known to be suboptimum, while allowing high survivorship (Gray 1999; Patton 1967). We housed crickets (diet-manipulated-as-adults group) or reared them (dietmanipulated-as-nymphs group) individually in 500-ml containers with cardboard shelter and water in cottonplugged vials. We noted the mass within $24 \mathrm{~h}$ of the adult moult (to $1 \mathrm{mg}$ ), and mass and pronotal width (to $0.01 \mathrm{~mm}$ ) immediately following song recording; for the nymphal diet group, we also noted starting mass and 
development time to adulthood and assessed fat reserve via extractions (see below).

\section{Courtship Song Recording and Analysis}

Crickets to be recorded were temperature acclimated to a recording room for a minimum of $24 \mathrm{~h}$ prior to recording. We placed a nonvirgin stock female into the male's container, removed the cardboard shelter and water vial, and replaced the normal container lid with a screen-mesh lid. Nonvirgin females were used because they are more reluctant to mate than virgin females. Use of nonvirgin females is ecologically realistic given the levels of female remating in this species (Solymar \& Cade 1990). For the purposes of this study, use of nonvirgin females was advantageous because it allowed longer courtship song recordings and because extended courtship is more likely than short courtship to reveal condition or energetic effects on song. Because last-male sperm precedence in this species is high (ca. 72\%: Backus \& Cade 1986) males are not expected to alter mating effort with respect to female mating status. We recorded courtship song in a sound-insulated chamber using a Linear X M51 measurement microphone ( $\pm 1 \mathrm{~dB}$ from $10 \mathrm{~Hz}$ to $40 \mathrm{kHz})$ and a Tascam DA-P1 digital audio tape recorder $(44.1 \mathrm{kHz}$ sample rate, $\pm 1 \mathrm{~dB}$ from $20 \mathrm{~Hz}$ to $20 \mathrm{kHz}$ ). Recording temperature was noted to the nearest $0.1^{\circ} \mathrm{C}$, and ranged from 23.0 to $26.0^{\circ} \mathrm{C}$ (mean \pm SD: $24.6 \pm 0.6^{\circ} \mathrm{C}$ ). Males ranged from 8 to 24 days age postadult moult at recording (mean \pm SD: $13.2 \pm 3.4$ ).

To retain statistical power requires limiting the number of separate statistical tests performed, which effectively means limiting the number of song components tested. We selected three song components to measure a priori, based on two criteria: whether or not the song components are subject to female preference (Fitzpatrick et al., unpublished data) and their probable energetic expense, the rationale being that more energetically expensive song components are more likely to be condition dependent (Zahavi 1975, 1977, 1991). The three song components were (Fig. 1) the interphrase interval (sexually selected, energetic expense), the high-frequency tick period (reciprocal of tick rate, energetic expense), and the number of low-frequency ticks per high-frequency tick period (energetic expense). We have no measurements of the energetic expense of the courtship song components in this species, however, a large body of literature indicates that energetic expense is a simple function of the number and repetition rate of song pulses. Faster song with more pulses requires more energy (e.g. Prestwich \& Walker 1981; Prestwich 1994; Hoback \& Wagner 1997; Hack 1998). Kavanagh (1987) summarized data for eight species of gryllids and tettigoniids (crickets and katydids) and showed that energy use averages $2.5 \times 10^{-5} \pm 0.9 \times 10^{-5} \mathrm{ml}$ of oxygen per wingstroke per gram (range 1.46-4.15). Furthermore, courtship song was found to be approximately 2.5 times more energetically expensive than calling song in Acheta domesticus (Hack 1998). Thus we consider the energetic expense of song production to be firmly established.
We transferred approximately $10 \mathrm{~s}$ of courtship song per male to 'aiff' files, which we then high-pass filtered at $0.5 \mathrm{kHz}$, calibrated amplitude to a known standard and analysed using Canary v1.2.4 (Cornell Laboratory of Ornithology, Ithaca, New York, U.S.A.). We made 15 measurements per song character (for one male, only 12 measures of the number of low-frequency ticks could be made). We used the median value for each song character for each male in the analysis. Final sample sizes were: bad diet as adults, $N=25$; good diet as adults, $N=29$; bad diet as nymphs, $N=24$; good diet as nymphs, $N=27$.

The cricket courtship song components measured here show little temporal variation and are significantly repeatable across the entire natural life span of males (interphrase interval repeatability: 47\%; the number of low-frequency ticks per phrase repeatability: 31\%; highfrequency tick rate (the reciprocal of high-frequency tick period) repeatability: 21\%; Fitzpatrick et al., unpublished data). Thus we consider that $10 \mathrm{~s}$ provided a statistically adequate sample of song. Female crickets, especially nonvirgin ones, typically sample a longer duration of song.

\section{Assessing Energetic Fat Reserve}

Immediately following courtship song recording, weighing and measuring, we individually preserved individuals of the diets-manipulated-as-nymphs group in vials with $70 \%$ ethanol. This gave us the opportunity, some time later, to extract the fat from these individuals and determine the degree to which condition measured as residual mass reflects condition measured as energetic fat reserve. Unfortunately, we did not preserve crickets from the diets-manipulated-as-adults group. To estimate energetic fat reserve, we used petroleum ether extractions in a refluxing Soxhlet apparatus (see Dobush et al. 1985; Marden 1989). We performed extractions separately for each cricket. We removed the crickets from the preservation vials, and dissected out the crop, stomach and hindgut to exclude fat from within the food as opposed to fat within the cricket per se. We then air dried the crickets for a minimum of $24 \mathrm{~h}$, and then further dried them in a $70{ }^{\circ} \mathrm{C}$ drying oven to constant mass (ca. $14 \mathrm{~h}$ ). We similarly dried and weighed Soxhlet thimbles. We completely macerated each cricket in its thimble using a blunt probe, and recorded the combined mass of the cricket and thimble. We then extracted the fats in the Soxhlet for $6 \mathrm{~h}$ and oven dried the remainder plus the thimble to constant mass and obtained the postextraction dry mass. All masses for the Soxhlet extraction portion of this study were measured to $0.1 \mathrm{mg}$. We calculated total fat extracted for each cricket as the pre-extraction mass minus the postextraction mass.

\section{Statistical Analysis}

We analysed the data with SPSS v.10.0. We calculated the residual mass measure of male condition from regressions of recording mass onto pronotal width. We performed the regressions separately for the nymphal and 
adult diet groups. We think that residual mass based on separate regressions is preferable as it standardizes mean condition within each group to zero. None the less, our results did not differ using the residual mass measure of condition based on a pooled regression (the correlation between male residual masses based on separate regressions and a pooled regression: $r=0.915, N=105$, $P<0.0001)$.

To avoid further the problems of low statistical power associated with multiple tests, we conducted a multivariate analysis of covariance (MANCOVA) for the three song variables together. We entered recording temperature and male age as covariates, and treated diet (good or bad) and the life stage at which the diets were imposed (at adulthood or as nymphs) as fixed effects.

We tested whether or not the diets had a significant effect on male residual mass using univariate analysis of variance (ANOVA) with diet and stage as fixed effects. For the diet-manipulated-as-nymphs subset of the data, we also tested for diet effects on development time, fat reserve and mass gained from the initiation of the experiment to the adult moult.

\section{RESULTS}

\section{Dietary Effects on Courtship Song}

Male courtship song was unaffected by dietary treatment (Fig. 2) (MANCOVA: $F_{3,97}=0.63, P=0.599$ ) and there was no stage $*$ diet interaction (MANCOVA: $F_{3,97}=0.61$, $P=0.613)$. The univariate effects of diet were all nonsignificant (interphrase interval length: $F_{1,99}=1.25, P=0.267$; high-frequency tick period: $F_{1,99}=0.70, P=0.406$; number of low-frequency ticks: $F_{1,99}=0.03, P=0.853$ ).

Both covariates, temperature and recording age, were significant (temperature: $F_{3,97}=5.55, P<0.001$; recording age: $\left.F_{3,97}=2.91, P<0.038\right)$. The significance of temperature as a covariate was due to its effect on interphrase interval length $\left(F_{1,99}=8.98, P<0.003\right)$ and its effect on the high-frequency tick period $\left(F_{1,99}=7.71, P<0.007\right)$; the number of low-frequency ticks was unaffected by temperature $\left(F_{1,99}=0.61, P=0.435\right)$. The multivariate significance of male recording age was due to a weakly nonsignificant effect on the high-frequency tick period $\left(F_{1,99}=3.50 P=0.064\right)$; no effect was observed on either interphrase interval length or the number of lowfrequency ticks $\left(F_{1,99}=1.47, P=0.229\right.$ and $F_{1,99}=0.88$, $P=0.351$, respectively).

\section{Dietary Effects on Residual Mass, Weight Gain, Development Time and Energetic Reserve}

Male residual mass was affected by diet when the diets were imposed at the nymphal stage but not when imposed at the adult stage (ANOVA: diet: $F_{1,101}=3.63$, $P=0.060$; diet $*$ stage $F_{1,101}=10.61, P<0.002$; a main effect of stage would be meaningless as residuals were constrained to a mean of zero in each group; Fig. 3).

Change in body mass from the adult moult to song recording time did not differ by diet in either the
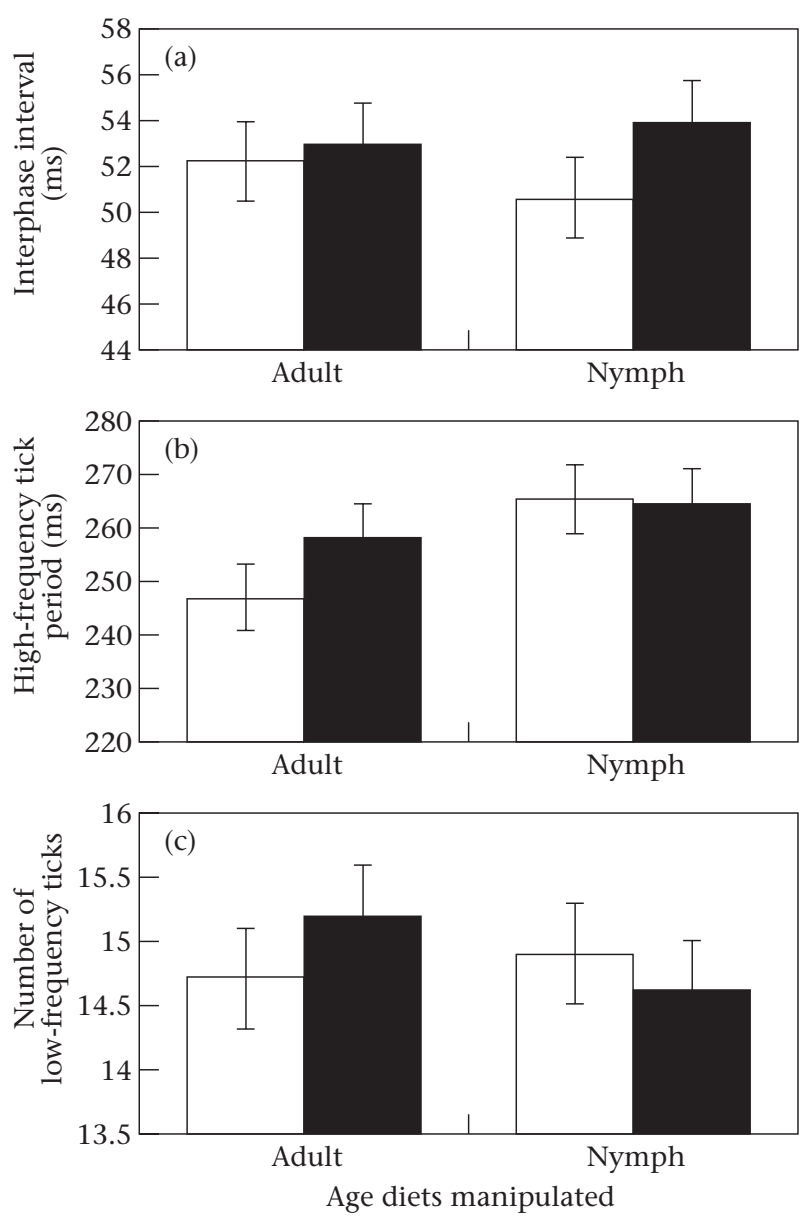

Figure 2. Means $\pm S E$ of the song components as a function of dietary treatment and the life stage at which the diet was imposed. (a) Interphrase interval length, (b) high-frequency tick period, and (c) the number of low-frequency ticks. $\square$ : The good diet group; : the bad diet group. Means are corrected for the covariates temperature and recording age (see text).

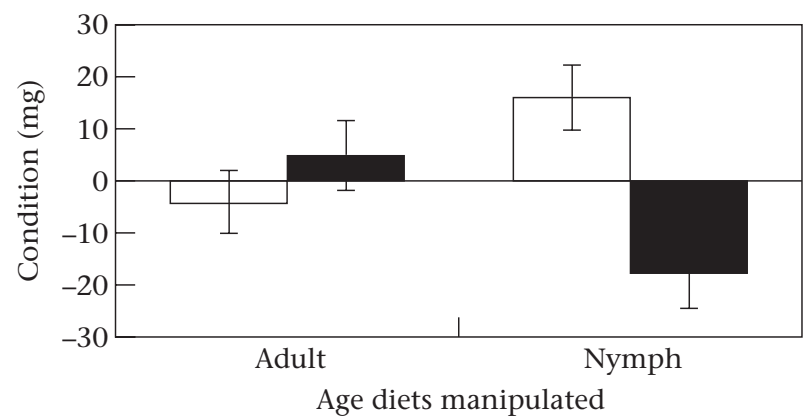

Figure 3. Male condition measured as residual mass as a function of dietary treatment and the life stage at which the diet was imposed. Bars are means and standard errors. $\square$ : The good diet group; $\square$ : the bad diet group.

diets-manipulated-as-nymphs or the diets-manipulatedas-adults groups, although the results were suggestive for the diets-as-adults group (diets-as-nymphs: good diet: $26 \pm 44 \mathrm{mg}$; bad diet: $23 \pm 29 \mathrm{mg}$; $t$ test unequal variance: $t_{45}=0.307, P=0.760$; diets-as-adults: good diet: 


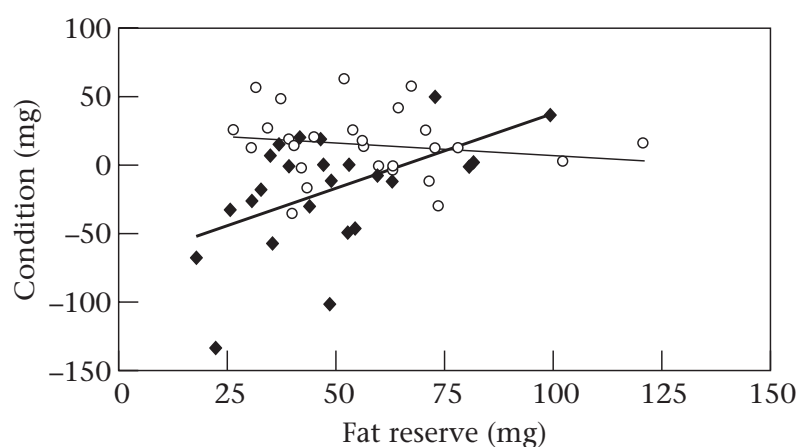

Figure 4. The relationship between fat reserve and 'condition' assessed as residual mass. The black diamonds and thick darkened line represent the significant correlation for crickets reared on the bad diet, whereas the open circles and thin line represent the nonsignificant correlation for crickets reared on the good diet.

$29 \pm 37 \mathrm{mg}$; bad diet: $49 \pm 44 \mathrm{mg} ; t$ test equal variance: $\left.t_{52}=1.817, P=0.075\right)$.

Nymphal development time did not differ as a function of diet (mean \pm SE: good diet: $19.0 \pm 0.3$ days; bad diet: $19.1 \pm 0.3$ days; $F_{1,49}=0.04, P=0.851$ ). Mass gained during development did differ by diet (mean \pm SE: good diet: $408.4 \pm 12.3 \mathrm{mg}$; bad diet: $356.9 \pm 13.1 \mathrm{mg} ; F_{1,49}=8.211$, $P<0.006)$.

Male energetic fat reserve, as estimated by Soxhlet extraction, was clearly related to residual mass when the nymphs were reared on the bad diet, but not when they were reared on the good diet (Fig. 4). For bad diet nymphs, the correlation was strong and significant ( $r=0.52, N=24, P=0.009$ ), whereas for good diet nymphs the correlation was nonexistent $(r=-0.16, N=27$, $P=0.424)$. Nymphs reared on the good and bad diets did not differ significantly in average fat reserve (means \pm SE: good diet: $56.7 \pm 4 \mathrm{mg}$ : bad diet: $48.5 \pm 4 \mathrm{mg}$ ), although the difference was suggestive and close to significance $\left(t_{49}=1.39\right.$, one-tailed $\left.P=0.085\right)$.

\section{Residual Mass and Energetic Fat Reserve Effects on Song}

The partial correlations of the song variables with male residual mass, controlling for temperature and age, were all nonsignificant (diet-manipulated-as-nymphs, $N=51$ : interphrase interval length: $r=-0.11, P=0.437$; high-frequency tick period: $r=-0.09, P=0.525$; number of low-frequency ticks: $r=-0.05, P=0.746$; dietmanipulated-as-adults, $N=54$ : interphrase interval length: $r=0.09, P=0.506$; high-frequency tick period: $r=-0.12$, $P=0.399$; number of low-frequency ticks: $r=-0.15$, $P=0.276)$.

There were similarly no effects of energetic fat reserve on song. Considering all males whose diets were manipulated as nymphs, the partial correlations (controlling for temperature and age) of energetic fat reserve with interphrase interval, high-frequency tick period and number of low-frequency ticks were $r=-0.08, r=-0.19$ and $r=-0.18$, respectively (all NS). Within the subgroup of males that received the good diet, the same correlations were $r=-0.10, r=-0.17$ and $r=-0.12$, respectively (all NS). For males on the bad diet, the same correlations were $r=0.07, r=-0.22$ and $r=-0.28$, respectively (all NS).

Males producing shorter interphrase intervals did not compensate in other portions of the song. The interphrase interval length was not correlated with the high-frequency tick period (partial $r$ s controlling for temperature and age: diets-as-nymphs: $r_{47}=0.17, P=0.234$; diets-as-adults: $\left.r_{50}=0.13, P=0.343\right)$ nor the number of low-frequency ticks (partial $r$ s controlling for temperature and age: diets-as-nymphs: $r_{47}=-0.09, P=0.558$; diets-asadults: $\left.r_{50}=-0.09, P=0.507\right)$.

\section{DISCUSSION}

There are two major findings of general importance that come from this study. First, male sexual advertisement is not necessarily condition dependent, at least not within the ecologically relevant time frame of typical courtship. Second, residual mass, which is a commonly used measure of condition, has limitations, particularly for organisms under relatively benign environmental regimes. We believe that we have made an experimental demonstration that male courtship song is not condition dependent. Courtship song was unaffected by dietary treatment and was unrelated to condition measured as either residual mass or energetic fat reserve. Similarly, Wagner \& Reiser (2000) manipulated the diet of a related species of field cricket, Gryllus lineaticeps, and found no change in courtship song chirp rate (equivalent to the high-frequency tick period of this study). These results are important to an understanding of sexual communication in crickets, but may also have broader significance for the study of sexual communication generally.

The cost, and condition dependence, of sexual signals is important to major theories of mate choice. A currently widely accepted view is that sexual signals need be expensive in order to retain their honesty. This is based on the ideas put forward by Zahavi $(1975,1977,1991)$, with a number of more recent variants (e.g. Kodric-Brown \& Brown 1984; Andersson 1986; Folstad \& Karter 1992). These papers have made major contributions to our understanding of sexual signalling and mate choice (empirical studies reviewed in Johnstone 1995; Møller \& Alatalo 1999). However, for the most part, the theoretical work has assumed relatively long-lived iteroparous organisms (e.g. birds, mammals, fish) in which there may be very real long-term fitness costs to a low-quality male of signalling at a 'deceptively' high level, given high average survivorship. In such systems, low-quality males that signal at too high a rate for their true quality pay a substantial long-term fitness cost because of an increased chance of mortality and loss of future reproduction. In contrast, imagine species in which the probability of future survivorship is low on average. High-quality males in such a system may have an intermediate optimal signal rate that balances present and future reproduction. Low-quality males, however, may simply be selected to maximize their signalling at as high a rate as they can, come what may in terms of future reproduction. That is, low-quality males may have such low residual 
reproductive value that they may be better served by investing everything in current reproduction (see also Kokko 1997).

In summary, we have shown experimentally that male $G$. texensis courtship song is not condition dependent. We suggest that this finding is consistent with an interpretation of sexual signalling that incorporates the trade-off between current and future reproduction: low-quality males may in effect invest everything in current reproduction and thus signal at as high a rate as males in better condition. Thus even energetically expensive signals may not necessarily describe energetic reserve adequately and we caution that studies of condition effects in benign environments may have limited applicability to the field.

\section{Acknowledgments}

This study was financially supported by a Natural Sciences and Engineering Research Council of Canada operating grant to W. H. Cade. We thank Bill Cade, Mark Fitzpatrick, Michael Greenfield and two anonymous referees for many helpful comments. We are particularly grateful for the suggestion of Soxhlet fat extraction.

\section{References}

Adamo, S. A. \& Hoy, R. R. 1994. Mating behaviour of the field cricket Gryllus bimaculatus and its dependence on social and environmental cues. Animal Behaviour, 47, 857-868.

Alexander, R. D. 1961. Aggressiveness, territoriality, and sexual behavior in field crickets (Orthoptera: Gryllidae). Behaviour, 17, 130-223.

Andersson, M. 1986. Evolution of condition-dependent sex ornaments and mating preferences: sexual selection based on viability differences. Evolution, 40, 804-816.

Andersson, M. 1994. Sexual Selection. Princeton, New Jersey: Princeton University Press.

Backus, V. L. \& Cade, W. H. 1986. Sperm competition in the field cricket Gryllus integer (Orthoptera: Gryllidae). Florida Entomologist, 69, 722-728.

Balakrishnan, R. \& Pollack, G. S. 1996. Recognition of courtship song in the field cricket, Teleogryllus oceanicus. Animal Behaviour, 51, 353-366.

Balakrishnan, R. \& Pollack, G. S. 1997. The role of antennal sensory cues in female responses to courting males in the cricket Teleogryllus oceanicus. Journal of Experimental Biology, 200, 511-522.

Boake, C. R. B. 1984. Male displays and female preferences in the courtship of a gregarious cricket. Animal Behaviour, 32, 690-697.

Bolger, T. \& Connolly, P. L. 1989. The selection of suitable indices for the measurement and analysis of fish condition. Journal of Fish Biology, 26, 171-182.

Brown, W. D. 1997. Female remating and the intensity of female choice in black-horned tree crickets, Oecanthus nigricornis. Behavioral Ecology, 8, 66-74.

Brown, W. D., Wideman, J., Andrade, M. C. B., Mason, A. C. \& Gwynne, D. T. 1996. Female choice for an indicator of male size in the song of the black-horned tree cricket, Oecanthus nigricornis (Orthoptera: Gryllidae: Oecanthinae). Evolution, 50, 2400-2411.

Burk, T. 1983. Male aggression and female choice in a field cricket (Teleogryllus oceanicus): the importance of courtship song. In: Orthopteran Mating Systems: Sexual Competition in a Diverse Group of Insects (Ed. by D. T. Gwynne \& G. K. Morris), pp. 97-119. Boulder, Colorado: Westview Press.

Candolin, U. 1999. The relationship between signal quality and physical condition: is sexual signalling honest in the three-spined stickleback? Animal Behaviour, 58, 1261-1267.

Crankshaw, O. S. 1979. Female choice in relation to calling and courtship songs in Acheta domesticus. Animal Behaviour, 27, 1274-1275.

Dobush, G. R., Ankney, C. D. \& Krementz, D. G. 1985. The effect of apparatus, extraction time, and solvent type on lipid extractions of snow geese. Canadian Journal of Zoology, 63, 1917-1920.

Doherty, J. A. 1985. Phonotaxis in the cricket, Gryllus bimaculatus DeGeer: comparisons of choice and no-choice paradigms. Journal of Comparative Physiology A, 157, 279-289.

Doherty, J. A. \& Callos, D. 1991. Acoustic communication in the trilling field cricket, Gryllus rubens (Orthoptera: Gryllidae). Journal of Insect Behavior, 4, 67-82.

Doherty, J. A. \& Howard, D. J. 1996. Lack of preference for conspecific calling songs in female crickets. Animal Behaviour, 51, 981-989.

Doherty, J. A. \& Storz, M. M. 1992. Calling song and selective phonotaxis in the field crickets, Gryllus firmus and G. pennsylvanicus (Orthoptera: Gryllidae). Journal of Insect Behavior, 5, 555-569.

Droney, D. C. 1998. The influence of the nutritional content of the adult male diet on testis mass, body condition and courtship vigour in a Hawaiian Drosophila. Functional Ecology, 12, 920-928.

Folstad, I. \& Karter, A. J. 1992. Parasites, bright males, and the immunocompetence handicap. American Naturalist, 139, 603-622.

Forrest, T. G. \& Green, D. M. 1991. Sexual selection and female choice in mole crickets (Scapteriscus: Gryllotalpidae): modelling the effects of intensity and male spacing. Bioacoustics, 3, 93-109.

Gray, D. A. 1997. Female house crickets, Acheta domesticus, prefer the chirps of large males. Animal Behaviour, 54, 1553-1562.

Gray, D. A. 1999. Intrinsic factors affecting female choice in house crickets: time cost, female age, nutritional condition, body size, and size-relative reproductive investment. Journal of Insect Behavior, 12, 691-700.

Gray, D. A. \& Cade, W. H. 1999a. Quantitative genetics of sexual selection in the field cricket, Gryllus integer. Evolution, 53, 848-854.

Gray, D. A. \& Cade, W. H. 1999b. Sex, death and genetic variation: natural and sexual selection on cricket song. Proceedings of the Royal Society of London, Series B, 266, 707-709.

Gray, D. A. \& Cade, W. H. 2000. Sexual selection and speciation in field crickets. Proceedings of the National Academy of Sciences, U.S.A., 97, 14449-14454.

Gwynne, D. T. \& Bailey, W. J. 1999. Female-female competition in katydids: sexual selection for increased sensitivity to a male signal? Evolution, 53, 546-551.

Hack, M. A. 1998. The energetics of male mating strategies in field crickets (Orthoptera: Gryllinae: Gryllidae). Journal of Insect Behavior, 11, 853-867.

Hedrick, A. V. 1986. Female preferences for male calling bout duration in a field cricket. Behavioral Ecology and Sociobiology, 19, 73-77.

Hedrick, A. V. \& Weber, T. 1998. Variance in female responses to the fine structure of male song in the field cricket, Gryllus integer. Behavioral Ecology, 9, 582-591.

Hoback, W. W. \& Wagner, W. E., Jr. 1997. The energetic cost of calling in the variable field cricket, Gryllus lineaticeps. Physiological Entomology, 22, 286-290.

Johnstone, R. A. 1995. Sexual selection, honest advertisement and the handicap principle: reviewing the evidence. Biological Reviews of the Cambridge Philosophical Society, 70, 1-65. 
Kavanagh, M. W. 1987. The efficiency of sound production in two cricket species, Gryllotalpa australis and Teleogryllus commodus (Orthoptera: Grylloidea). Journal of Experimental Biology, 130, 107-119.

Knapp, R. A. 1995. Influence of energy reserves on the expression of a secondary sexual trait in male bicolor damselfish, Stegastes pertitus. Bulletin of Marine Science, 57, 672-681.

Kodric-Brown, A. \& Brown, J. H. 1984. Truth in advertising: the kinds of traits favored by sexual selection. American Naturalist, 124, 309-323.

Kokko, H. 1997. Evolutionary stable strategies of age-dependent sexual advertisement. Behavioral Ecology and Sociobiology, 41, 99-107.

Libersat, F., Murray, J. A. \& Hoy, R. R. 1994. Frequency as a releaser in the courtship song of two crickets, Gryllus bimaculatus (deGeer) and Teleogryllus oceanicus: a neuroethological analysis. Journal of Comparative Physiology A, 174, 485-494.

Marden, J. H. 1989. Bodybuilding dragonflies: costs and benefits of maximizing flight muscle. Phyiological Zoology, 62, 505-521.

Milinski, M. \& Bakker, T. C. M. 1990. Female sticklebacks use male coloration in mate choice and hence avoid parasitized males. Nature, 344, 330-333.

Møller, A. P. 1994. Male ornament size as a reliable cue to enhanced offspring viability in the barn swallow. Proceedings of the National Academy of Sciences, U.S.A., 91, 6929-6932.

Møller, A. P. \& Alatalo, R. V. 1999. Good-genes effects in sexual selection. Proceedings of the Royal Society of London, Series B, 266, 85-91.

Nelson, C. M. \& Nolen, T. G. 1997. Courtship song, male agonistic encounters, and female mate choice in the house cricket, Acheta domesticus (Orthoptera: Gryllidae). Journal of Insect Behavior, 10, 557-570.

Patton, R. L. 1967. Oligidic diets for Acheta domesticus (Orthoptera: Gryllidae). Annals of the Entomological Society of America, 60, 1238-1242.

Pollack, G. S. \& Hoy, R. R. 1979. Temporal pattern as a cue for species-specific calling song recognition in crickets. Science, 204, 429-432.

Prestwich, K. N. 1994. The energetics of acoustical signaling in anurans and insects. American Zoologist, 34, 625-643.

Prestwich, K. N. \& Walker, T. J. 1981. Energetics of singing in crickets: effect of temperature in three trilling species (Orthoptera: Gryllidae). Journal of Comparative Physiology, 143, 199-212.

Radford, A. N. \& Blakely, J. K. 2000. Is variation in brood sex ratios adaptive in the great tit (Parus major)? Behavioral Ecology, 11, 294-298.
Shaw, K. L. 2000. Interspecific genetics of mate recognition: inheritance of female acoustic preference in Hawaiian crickets. Evolution, 54, 1303-1312.

Shaw, K. L. \& Herlihy, D. P. 2000. Acoustic preference functions and song variability in the Hawaiian cricket Laupala cerasina. Proceedings of the Royal Society of London, Series B, 267, 577-584.

Sheldon, B. C., Merila, J., Qvarnstrom, A., Gustafsson, L. \& Ellegren, H. 1997. Paternal genetic contribution to offspring condition predicted by size of male secondary sexual character. Proceedings of the Royal Society of London, Series B, 264, 297-302.

Simmons, L. W. 1988. The calling song of the field cricket, Gryllus bimaculatus (De Geer): constraints on transmission and its role in intermale competition and female choice. Animal Behaviour, 36, 380-394.

Simmons, L. W. \& Ritchie, M. G. 1996. Symmetry in the songs of crickets. Proceedings of the Royal Society of London, Series B, 263, 305-311.

Simmons, L. W. \& Zuk, M. 1992. Variability in call structure and pairing success of male field crickets, Gryllus bimaculatus: the effects of age, size and parasite load. Animal Behaviour, 44, 1145-1152.

Solymar, B. \& Cade, W. H. 1990. Heritable variation for female mating frequency in field crickets, Gryllus integer. Behavioral Ecology and Sociobiology, 26, 73-76.

Ulagaraj, S. M. \& Walker, T. J. 1975. Response of flying mole crickets to three parameters of synthetic songs broadcast outdoors. Nature, 253, 530-532.

Wagner, W. E., Jr. 1996. Convergent song preferences between female field crickets and acoustically orienting parasitoid flies. Behavioral Ecology, 7, 279-285.

Wagner, W. E., Jr \& Hoback, W. W. 1999. Nutritional effects on male calling behaviour in the variable field cricket. Animal Behaviour, 57, 89-95.

Wagner, W. E., Jr \& Reiser, M. G. 2000. The importance of calling song and courtship song in female mate choice in the variable field cricket. Animal Behaviour, 59, 1219-1226.

Wagner, W. E., Jr, Murray, A.-M. \& Cade, W. H. 1995. Phenotypic variation in the mating preferences of female field crickets, Gryllus integer. Animal Behaviour, 49, 1269-1281.

Zahavi, A. 1975. Mate selection: a selection for a handicap. Journal of Theoretical Biology, 53, 205-214.

Zahavi, A. 1977. The cost of honesty (further remarks on the handicap principle). Journal of Theoretical Biology, 67, 603-605.

Zahavi, A. 1991. On the definition of sexual selection, Fisher's model, and the evolution of waste and of signals in general. Animal Behaviour, 42, 501-503. 